V. 12 N. 1

JAN-ABR 2016

ISSN 2317-6172

Recibido: 14.02.2013

Aprobado: 21.10 .2015

DOI: http://dx.doi.org/10.1590/ 2317-6172201604

1 Universidad de los Andes Santiago de Chile

\section{Obligatoriedad de la ley humana y leyes puramente penales en Domingo de Soto y Francisco Suárez}

THE BINDING FORCE OF HUMAN LAW AND STRICTLY PENAL LAWS IN DOMINGO DE SOTO AND FRANCISCO SUÁREZ

Sebastián Contreras ${ }^{1}$

\section{Resumen}

La pregunta de si la ley humana obliga en conciencia tiene un lugar central en la filosofía jurídica de la Escolástica española, en particular, en los escritos de Domingo de Soto y de Francisco Suárez. Soto y Suárez - que marcan, respectivamente, el inicio y el fin de la Escolástica salmantina del siglo XVI-construyen su teoría de la ley humana en torno a una suerte de deber general de obediencia del derecho, indicando que hay casos en que incluso se deben cumplir los mandatos de la ley injusta. En este contexto, me he propuesto examinar la teoría general de Soto y de Suárez sobre la fuerza obligatoria de la ley humana y me refiero a dos aplicaciones de esta teoría: la cuestión de las leyes meramente penales y el problema de la obligatoriedad de la ley injusta.

\section{Palabras clave}

Domingo de Soto; Francisco Suárez; ley humana; ley meramente penal; ley injusta.

\section{Abstract}

The question of whether the human law obligates consciousness occupies a central position in the philosophy of law of Spanish Scholastic, especially in the works of Domingo de Soto and Francisco Suárez. Soto and Suárez - which mark the beginning and the end of the sixteenth century Salamanca Scholastic-have developed their theory of human law around a kind of general duty of obedience to the Law, including instances where unfair laws must be observed. In this context, I intend to examine the general theory of Soto and Suárez about the binding force of human law. I will focus on two applications of this theory: the question of strictly penal laws and the issue of the mandatory nature of the unfair law.

\section{Keywords}

Domingo de Soto; Francisco Suárez; human law; strictly penal laws; unfair law. 
a pregunta por la ley humana, por su naturaleza y funciones, es uno de los temas principales de la teoría del derecho de la Escolástica española. La propia definición de ley, que los escolásticos toman de STh I-II, q. 90, a. 4, depende de la manera como se entiendan la ley positiva y el poder humano. Por ejemplo, los escolásticos hablan de "promulgación”, "poder", "bien común”, etc., cuando tratan de la ley natural y de la ley eterna, incluso cuando hablan de la ley divina; pero estas categorías pertenecen, en estricto rigor, a la teoría de la ley humana y del poder civil.

En el contexto de esta pregunta, los escolásticos españoles se han preocupado, especialmente, por la cuestión de los límites de la potestad normativa de los hombres: qué pueden mandar y qué no pueden mandar los gobernantes, y hasta qué punto obligan las leyes que estos imponen. Dicen, a este respecto, que las normas del derecho humano, si son justas, obligan en el fuero interno, pues encarnan la justicia de la ley natural, que es, por esencia, obligatoria. Y señalan que el poder de dictar leyes positivas no se reduce a la potestad de "declarar" el derecho natural: los hombres también pueden crear nuevo derecho. Por esta razón, los autores de la Escolástica del siglo XVI se oponen a las ideas de Gerson, que sostiene que las leyes humanas solo ejercen una función de "declaración" de la ley natural.

Domingo de Soto y Francisco Suárez, que son los autores en los que concentraré mi trabajo, no aceptan la postura de Gerson. Expresan que, desde Aristóteles, se viene defendiendo la hipótesis de que sí es posible dictar preceptos de justicia nuevos, inexistentes según el derecho natural. Señalan que el poder para obligar en conciencia a los ciudadanos no tendría sentido si las leyes positivas fueran simples desarrollos de la ley natural. En ese caso, la causa de la obligación de la ley humana no sería la autoridad de los hombres, sino el mismo derecho natural, al que fácilmente se podrían reducir esos preceptos, lo que es contrario a la distinción clásica entre ley o derecho positivo y ley o derecho natural.

Si bien los escolásticos hablan de la obligatoriedad de la ley humana a propósito de la ley justa, admiten que las normas injustas pueden obligar en algunos casos. No creen, así, que la ley injusta deba ser resistida a todo evento. Proponen distinciones, matices, porque, anotan, los ciudadanos no pueden causar un desorden mayor que el que ocasiona una ley contraria al bien humano. Sentado lo anterior, quisiera mostrar las principales conclusiones de Soto y de Suárez sobre el problema de la fuerza obligatoria de la ley humana. Con este propósito, he decidido dividir mi exposición en tres partes: en primer lugar, me referiré a la tesis general de estos autores; en segundo lugar, me centraré en la cuestión de las leyes meramente penales; y, en tercer lugar, expondré la doctrina de Soto y de Suárez sobre la obligatoriedad de la ley injusta. Tanto la cuestión de la ley meramente penal como el tema de la ley injusta no son más que aplicaciones del problema general de la obligatoriedad de la ley humana.

\section{LA OBLIGATORIEDAD DE LA LEY HUMANA}

La ley humana, en la medida en que se deriva de la ley natural, es justa y tiene fuerza para 
obligar. Esta es la tesis fundamental de la Escolástica española. Aunque con distintos matices, todos los autores de la Escolástica del siglo XVI asumen como idea rectriz el carácter obligatorio de las leyes positivas. Así se lee, por ejemplo, en Francisco de Vitoria, Bartolomé Carranza, Luis de León y Luis de Molina. La misma idea se repite en Domingo Báñez, Gabriel Vázquez y Francisco de Araújo.

Soto, al interior de esta tradición, asume la obligatoriedad de la ley humana como un principio general de su proyecto filosófico (De iustitia et iure, IV, 6, 4; V, 8, 4). Expone que la fuerza obligatoria de la ley positiva se deriva de su conformidad con la ley natural, y subraya que "obligar en conciencia" equivale a "obligar bajo pecado mortal" (VI, 9, un.). De igual manera, expresa que "obligar a culpa en el fuero de la conciencia hiere a las almas", por lo que "obligar en conciencia" es sinónimo de "obligar en el fuero interno", pues se crea una obligación moral —o interna_ de actuar en la forma prescrita por la ley $(\mathrm{I}, 6,4)$.

En un texto poco estudiado, el manuscrito vaticano 782 (en adelante, De lege), Soto completa esta doctrina, al señalar que lo que se manda en la ley humana puede ser de tanta importancia para la sociedad que los hombres debieran estar dispuestos a cumplir la ley aun con peligro de muerte. El dominico no piensa que eso ocurra a diario. De esta forma, se opone a Cayetano, quien enseña que la ley positiva obliga de ordinario a sufrir la muerte, salvo cuando la autoridad, llevada por la compasión, no quiera obligar a tanto (In I-II, 96, 4). A este respecto, anota Soto:

respondemos con dos afirmaciones. En primer lugar, el príncipe, secular o eclesiástico, puede alguna vez, tratándose de problemas graves, obligar a cumplir la ley aun con peligro de muerte. Así se deduce de Cayetano y del ejemplo propuesto: si los turcos atacaran a los cristianos y se diera una ley que los obligara a tomar las armas, habría que ir a la guerra incluso con peligro de perder la vida. No obstante, hay una segunda afirmación: ese caso, por lo general, no se da.Y no es lo mismo decir que la iglesia y el emperador pueden obligar bajo peligro de muerte que decir que la iglesia y el emperador pueden obligar incluso con peligro de muerte. No hay duda de que la ley del ayuno obliga ad mortale, pero si alguien me amenaza de muerte por cumplir esa ley, me sería lícito romper el ayuno, a menos que fuera por menosprecio de la ley (De lege, f. 435).

En el pasaje paralelo de De iustitia et iure, se indica:

ante todo es cierto que lo que se manda puede ser de tanta importancia para la sociedad que su cumplimiento puede exigir hasta perder la vida. Puesto que cuando un príncipe manda a un soldado en tiempo de guerra defender un lugar, en que existe un peligro inminente para la patria, debe de estar dispuesto a perder antes la vida que abandonar dicho lugar.Y asimismo cuantas veces ordena una cosa bajo pena capital, es menester 
exponerse al peligro de muerte por observar la ley. Porque aunque el príncipe no sea en absoluto dueño de la vida, como Dios, sin embargo, habiendo causa, puede exponer los súbditos a la muerte, como el todo a las partes (I, 6, 4). ${ }^{1}$

El argumento basado en la relación del todo con la parte también está presente en De lege. Soto piensa que la ley humana gobierna al ciudadano a la manera como el todo gobierna las partes, o, como dice, a la manera como el cuerpo gobierna al brazo, "exigiéndole que lo defienda". Así, la autoridad instituye leyes con fuerza directiva para resolver los distintos problemas de coordinación y para que los ciudadanos promuevan y participen del bien común; y la herramienta de que dispone para exigir a sus ciudadanos que cumplan sus mandatos es la fuerza (De lege, f. 433v). No hay que olvidar que la vis coactiva es un elemento de la esencia de la ley humana para los autores de la Escolástica española. También lo es para santo Tomás y para los pensadores de la Escolástica medieval.

La pregunta por la fuerza obligatoria de la ley humana no es trivial en la primera mitad del siglo XVI. La tesis gersoniana, que niega que las leyes humanas obliguen en el fuero interno, se ha extendido rápidamente y es uno de los temas centrales de la filosofía de la ley de los autores luteranos —a los que Soto intenta hacer frente ${ }^{2}-$. Asume una concepción negativa de la ley, plantea que las leyes escritas entorpecen la vida humana, y rechaza la idea de que los hombres puedan crear nuevos principios de justicia, inexistentes según el derecho divino o natural.

Soto, que conoce los escritos de Gerson, se pregunta si la obligación ad culpam de la ley humana depende del juicio del gobernante. Es decir, si la autoridad, al dar una ley, puede no imponer una obligación bajo culpa moral. Su opinión es que la ley humana siempre obliga, que sobre los ciudadanos pesa un deber irrenunciable de cumplir los mandatos de la

1 Prosigue el texto: "tampoco es lo mismo obligar a pecado mortal y obligar aunque exista peligro de muerte. Porque la ley del ayuno nos obliga sin duda bajo pecado mortal; sin embargo si un tirano amenazara a uno con la muerte, si no quebrantare el ayuno, no sería pecado alguno que por fin la quebrantara, a no ser que quisiera obligar a ello por desprecio de la ley, porque entonces el cristiano estaría obligado a preferir la muerte. Porque aunque ciertamente debe preferirse morir a pecar, con todo se presume que la ley no obliga a tal extremo. Y por esto para saber si la ley obliga o no a sufrir la muerte, ha de tenerse en cuenta la importancia y gravedad de lo que manda. Y aún más, ni la misma ley divina nos obliga en todo lugar con semejante rigor" (De iustitia et iure, I, 6, 4).

2 Soto resume la posición de los autores luteranos en estos términos: "dice Lutero que Cristo ya impuso todas las leyes necesarias, y que no encomendó esa tarea a los hombres" (De lege, f. 433v). De igual manera: "en el tiempo pasado los waldenses y más tarde Juan Wiclef y últimamente sus legítimos herederos, los luteranos, han propagado el error de que ni en el pontífice ni en la iglesia existía poder alguno para establecer artículos de fe, o leyes para ordenar las costumbres. Así, efectivamente, se dice en el artículo veintisiete de los presentados al papa León. Por lo cual, dicen, solamente obligan en conciencia aquellos preceptos que se hallan explícitos en el Evangelio" (De iustitia et iure, I, 6, 4). 
ley humana aun sin consentir en esos mandatos. Lo anterior no significa que incluso las normas injustas impongan un deber absoluto o incondicionado de cumplimiento. No significa que Soto no contemple la posibilidad de resistirse a esa clase de leyes. Lo que significa es que la ley positiva no obliga solo per se, sino que también obliga per accidens, cuando la infracción o inobservancia de la ley produce un perjuicio mayor al que se tolera si se cumple la norma.

Soto remarca que la fuerza obligatoria de la ley no depende de expresiones como "obliga en conciencia" o "se manda bajo pecado mortal”. Señala que "no hay ley alguna que exprese esta circunstancia" (De iustitia et iure, I, 6, 4) y que "los legisladores no acostumbran a emplear estas palabras" (IV, 5, 3). Parte de la base de un deber general de obediencia del derecho: siempre que la ley humana sea justa obligará en conciencia. La obligación de la ley en el fuero de la conciencia es la regla. Existe, así, una presunción a favor de la ley positiva:

[l]a ley humana, tanto civil como canónica, si es justa, goza de autoridad y tiene virtud para obligar la conciencia de los súbditos. Prueba. Toda ley humana, según ya se dijo, se deriva de la eterna, mediante la ley natural, según se afirma en los Proverbios: 'Por mí reinan los reyes y establecen la justicia los legisladores'; en donde [...] con la primera parte se afirma que el poder de reinar es otorgado por Dios a los príncipes (De iustitia et iure, I, 6, 4).

Dando un paso adelante en su argumentación, Soto se pregunta si las leyes civiles y las leyes eclesiásticas obligan con la misma fuerza. Señala que "la obligación propia de la ley civil es menos evidente que la de la ley eclesiástica" (De lege, f. 433v), que "su obligación no consta con tal alto y seguro grado [...] como en las eclesiásticas" (De iustitia et iure, I, 6, 4), y que la infracción del derecho eclesiástico es herejía — además de falta moral—a diferencia de lo que ocurre con la infracción del derecho civil, que solo es falta moral (I, 6, 4). Pese a esto, el autor no piensa que la ley civil y la ley canónica sean realmente distintas, al menos no en lo que se relaciona con su fuerza de obligar. Tanto la ley civil como la eclesiástica son órdenes racionales dirigidos al bien público. Una y otra tienen fuerza para obligar en el fuero de la conciencia, y una y otra expresan la normatividad y justicia de la ley natural. En la práctica, la única diferencia reside en que "no es hereje el que afirma que las leyes de los príncipes no obligan bajo pecado mortal, aunque sí es temerario y se aparta de la opinión común" (De lege, f. 434). Prueba de lo anterior son las siguientes palabras de Soto:

en lo que se refiere a la fuerza de obligar, no hay que distinguir entre potestad eclesiástica y potestad civil. Solo Almain hace esta diferencia. Yo digo que, aun cuando el príncipe secular no tiene poder inmediato para dar penas eternas, sí tiene un poder mediato, porque hace que unos actos caigan dentro del orden de la virtud y que los contrarios se constituyan como males morales (f. 434v). 
La crítica a esta doctrina ya está presente en Vitoria. En su relección De potestate civili, el escolástico advierte que los transgresores de la ley humana, sea civil o eclesiástica, siempre son reos de culpa en el fuero de la conciencia. La tesis general de la Escolástica española es que la diferencia entre la obligación de la ley civil y la obligación de la ley eclesiástica es superflua, sin fundamento, porque la ley natural, que es el principio de la obligación, se hace igualmente presente en las determinaciones de la autoridad política o del papa. En este contexto, y hablando sobre la autoridad, señala Soto:

la eclesiástica la otorgó inmediatamente Cristo a la Iglesia por ley divina, y la civil brota de la ley natural, por la cual cualquier estado posee la facultad de administrarse a sí mismo; y esta misma facultad la pudo otorgar también a los reyes.Y de esta manera se sigue que como el Estado civil es también familia de Dios, del mismo modo que quien, quebrantando sus leyes, ofendiere al prójimo, es tenido por reo ante su tribunal, y quien, por el contrario, observando estas mismas leyes, hubiere sido bueno para el prójimo, es considerado digno de premio, así, exactamente igual, sucederá a quien quebrantare, u observare las leyes humanas establecidas por la potestad que él mismo otorgó. Y esto significa obligar en conciencia (De iustitia et iure, I, 6, 4). ${ }^{3}$

Suárez, en un tiempo muy difícil para la Escolástica (luchas de religión, implementación del concilio de Trento, pugna entre las órdenes religiosas, etc.), propone su propia síntesis de la filosofía escolástica de la ley apoyado en las ideas de Aristóteles, de Tomás de Aquino, Juan Duns Scoto, Tomás de Vio, Francisco de Vitoria, Alfonso de Castro y de Domingo de Soto. Parte del supuesto de que "la intención de obligar es esencial a la ley" (De legibus, III, $27,1)$ y de que los efectos de la ley “casi en su totalidad se reducen a la obligación” (III, 21, 1). Para Suárez, la obligación o deber es el efecto adecuado de la ley. No hay ley que no imponga una obligación. El poder humano es esencialmente legislativo, "por eso, afirma, no dudamos en general de la obligación, sino que la suponemos” (III, 21, 1).

Obligar en conciencia equivale a imponer una necesidad moral para actuar de cierta manera (III, 22, 2). La obligación de la ley vincula en el fuero interno, que es, como indica Suárez, el fuero de Dios. Puesto que el hombre no puede obligar en el fuero de Dios, porque la creatura no puede obligar a la manera del creador, parece que los hombres no pueden dictar leyes que obliguen en el fuero interno. Por eso surgió la opinión "que negaba que los magistrados civiles pudiesen con sus leyes obligar en conciencia” (III, 21, 4). Suárez, contra esta objeción, señala que:

3 Supuesta esta conclusión, añade Soto: "[o]brar contra una ley de un gobernante es un mal moral; por consiguiente, es un pecado ante Dios. El antecedente es claro; porque si la ley es justa, constituye una regla de la razón; y traspasar los límites de la razón, es un extravío, y por tanto un pecado” (De iustitia et iure, I, 6, 4). 
el legislador civil da las leyes como ministro de Dios y con poder recibido de Él; luego obliga en conciencia a obedecer. La consecuencia es clara, porque quien hace resistencia al ministro del rey en aquello en que es ministro y en cuanto que representa la persona del rey, es claro que hace resistencia al rey mismo, como aparece por el consentimiento de todos los hombres y por aquello: No te han desechado a ti sino a mí; luego en la trasgresión de esa ley hay una ofensa e injusticia contra Dios; luego sufre la conciencia; luego la ley misma obligaba en conciencia (III, 21, 6).

La obligación es el efecto propio (formal, dice a veces) de la ley humana. Lo es de tal modo que no es necesario que se exprese en la ley la intención de obligar en conciencia o bajo pecado mortal. Expone Suárez:

[n]i es siempre necesario que se exprese la intención de obligar en conciencia o bajo pecado mortal; más aún, eso apenas si se le ocurre hacerlo al legislador civil, y menos tratándose de infieles, para los cuales existe la misma razón.Y lo mismo sucede con el voto y la promesa, pues, si se hacen, inmediatamente obligan en conciencia aunque el que hace la promesa para nada haya pensado en la conciencia. Luego lo mismo sucede con la ley, ni hay razón alguna para que se necesite una intención más expresa (III, $27,1)$.

Siguiendo una estrategia similar a la de Soto, Suárez hace depender sus argumentos de una presunción a favor de la fuerza obligatoria de la ley humana. No cree que sea correcto hablar de la obligatoriedad de la ley civil como si fuera una cosa diferente de la obligatoriedad de la ley eclesiástica. Tanto el príncipe como la iglesia pueden obligar bajo culpa con sus mandatos. Sostener lo contrario es ajeno a la reflexión cristiana y supone no comprender la importancia que tiene el poder público en el recto gobierno de la vida humana.

Suárez es, quizá, más enfático que Soto al rechazar las posturas de Gerson, Almain y Lutero. ${ }^{4}$ Las considera falsas, y cree que pasan por alto la doctrina de los Padres y las enseñanzas de las Escrituras. En primer lugar, porque "los apóstoles enseñaron a los fieles convertidos ya a Cristo que obedeciesen a los reyes y autoridades", no solo para evitar el castigo, ni solo para evitar el escándalo, sino también porque las autoridades civiles son ministros de Dios. En segundo lugar, porque así lo entendieron y explicaron los Padres más antiguos, como san Ambrosio, Orígenes, Justino, Epifanio, etc. (Defensio fidei, III, 4, 4). En tercer lugar, porque una opinión como esa es contraria a la fe o muy cercana a ello (De legibus, III, 21, 5). En cuarto lugar, porque negar la fuerza obligatoria de la ley humana contraviene la razón natural,

4 Suárez advierte que Soto no ha sido lo suficientemente claro en su explicación de la fuerza obligatoria de la ley humana. Esto lo lleva a señalar que "Menchaca, Soto, Castro y otros no tienen por tan cierto que las leyes civiles obliguen en conciencia como las eclesiásticas” (De legibus, III, 21, 4). 
según la cual "el derecho divino y natural dicta que se deben observar las leyes justas que dan los príncipes legítimos" (III, 21, 7). Pero, sobre todo, porque "un gobierno sin poder coactivo es ineficaz y fácilmente se le desprecia” (III, 21, 8). De modo que imaginar una autoridad sin poder para obligar en conciencia es un imposible.

La opinión común de los herejes, dice Suárez, es que la ley humana no puede obligar bajo culpa; solo la ley divina tiene fuerza para imponer penas eternas o vincular en el fuero de Dios ("piensan esto los herejes que niegan que los soberanos tengan verdadero poder para dar leyes"):

entre los católicos parece pensar así Gerson, quien dice que únicamente Dios puede dar preceptos afirmativos y negativos que obliguen bajo pena de muerte eterna. De ahí deduce que cuantas veces parece que se peca contra la ley humana, no se incurre en culpa por la trasgresión de la ley humana sino de la divina, que va junta. Por consiguiente lo único que parece conceder a la ley humana es ser una explicación de la obligación que se contiene en la ley divina (III, 21, 4).

Esta doctrina, que afirma que la ley humana no puede mandar nada que no esté mandado por la ley divina, "no sin escándalo se aparta del modo general de hablar de los teólogos introduciendo además una manera de hablar ambigua que puede acarrear un sentido erróneo y contrario a las buenas costumbres". Ahora bien, aunque la fuerza de obligar de las leyes positivas se funda en los principios de la ley natural, por ejemplo, en el precepto natural que ordena obedecer a los superiores, no es correcto afirmar que las leyes humanas sean meras explicaciones o desarrollos de la ley natural. Las leyes humanas no son todas ellas deducciones de los preceptos morales. En realidad, la mayoría de las leyes humanas no se derivan de ese modo de la ley natural. La mayor parte de estas leyes se obtienen por determinación de un principio general en una norma especial. Por eso, anota Suárez, "la ley misma humana añade a las inmediatas una obligación en conciencia que no está contenida en los principios de la ley natural si no es mediante el imperio del poder humano" (III, 21, 9).

La determinación es la manera que tiene el autor para dar a la ley humana el poder de obligar en el fuero interno. No existen razones morales para crear un nuevo impuesto o prohibir acciones indiferentes. Es la autoridad la que crea esas razones morales cuando instituye o cambia una ley:

aunque la ley civil no se deduzca, por decirlo así, especulativamente por una rigurosa consecuencia de los principios de la ley natural, sino que la da la voluntad del legislador como una determinación suya, sin embargo, una vez tomada esta determinación, de los principios naturales se deduce — al menos de una manera práctica — que esa ley humana debe ser observada; de esta manera la obligación de la ley civil se dice que es efecto de la 
ley natural como de causa sustancial, no próxima sino — por así decirlo — universal y modificada por otra causa particular, que es la ley humana (II, 9, 12).

Aun cuando la fuerza obligatoria de la ley positiva proviene inmediatamente del poder normativo de la autoridad, que crea razones para actuar de una forma o de otra, esa fuerza de obligar depende en última instancia de la ley natural. La ley natural es el principio de corrección de las leyes humanas. Estas normas se dicen justas o injustas por comparación con aquella. De ahí que Suárez hable de la ley natural como de una "causa sustancial" de la obligatoriedad del derecho civil, aunque última o remota y modificada por una "causa segunda" o "particular", que es la autoridad de la república.

\section{Las leyes Penales puras (O PURAMente penales)}

Alfonso de Castro había propuesto que la ley humana se divide en preceptiva o moral, mixta y meramente penal. La ley puramente moral es aquella que manda o prohíbe una acción sin imponer una pena. Por su parte, la ley penal pura es la que nada manda o prohíbe, sino que solo impone una pena al que hace u omite una acción. La ley mixta, por último, es la que ordena hacer algo o lo prohíbe y, además, impone una sanción para quien la contravenga. Tanto la moral como la mixta obligan ad culpam, lo que no hace la ley puramente penal: impone una pena por su incumplimiento, pero no causa obligación alguna.

Entre los autores que siguen esta doctrina están Martín de Azpilcueta, Gregorio de Valencia, Juan de Salas y Francisco Suárez. Por el contrario, Soto niega que existan leyes de esta clase. Según escribe, las leyes humanas siempre obligan en el fuero interno. No se puede pensar en una ley que no sea obligatoria; de hecho, en general, las leyes humanas obligan a culpa grave (De iustitia et iure, I, 6, 4).

Soto piensa que la ley humana incluye ya en sí un precepto de obediencia ("el bien de la obediencia no proviene de la ley, sino que lo presupone”) y la obediencia, nota, es una virtud. "De lo cual se sigue que cuando alguno, sea gobernante secular, o prelado eclesiástico, quiere dar una ley que no obligue a pecado, debe de consignarlo expresamente" (I, 6, 4). Si bien Soto rechaza el merepenalismo, con esta idea, como con la tesis de que "la ley humana obliga muchas veces en conciencia” (III, 4, 5), se acerca peligrosamente a la doctrina de Castro y de Azpilcueta. Afirma, en este sentido, que hay normas que no obligan a culpa, como las constituciones de los dominicos, las cuales "no obligan a pecado, sino solamente a la pena, a no ser cuando se quebrantan contra precepto formal, o con desprecio" (I, 6, 4).

Soto tiene el problema de que santo Tomás, a quien comenta y en quien apoya sus afirmaciones, expresa que "hay alguna orden religiosa, como la orden de los predicadores, en que la infracción u omisión de la regla no obliga bajo culpa, ni mortal ni venial, sino solo a sufrir la pena establecida" (STh II-II, 186, 9). Ante esto, el dominico español no tiene más opciones que reconocer que "en nuestra orden existen leyes de esa clase" (De lege, f. 434), aunque 
enseguida indica "nuestras constituciones obligan en conciencia” (f. 434). De esa tensión entre el reconocimiento de normas puramente penales y la afirmación de que no puede haber ley penal que no obligue en conciencia, surgen los siguientes corolarios: (i) la diferencia entre ley puramente penal y ley penal que obliga a culpa carece de sentido; (ii) las leyes que parecen meramente penales, en realidad, son leyes que imponen tributos o precios, por ejemplo: la norma "quien exportare trigo fuera del reino, sea privado de él, o sufra tal castigo" sin duda obliga a pecado. Sin embargo, si lo que se intenta es reunir fondos y no evitar la venta del trigo, la ley no obliga a pecado. Y, en este caso, la condición impuesta tiene razón de tributo, no de pena o sanción (De iustitia et iure, I, 6, 5).

Las órdenes religiosas no son las únicas que pueden dictar normas que no obligan a culpa. "El príncipe puede dar leyes que no obligan a culpa de ningún modo [...] Y toda la sociedad puede dictar normas de esa clase, por ejemplo: establecer que quien haga esto lo pague, declarando, además, que esa ley no obliga bajo culpa”. Por lo general la ley humana obligará en el fuero interno, al menos a la pena. 5 "A no ser que la autoridad declare que su ley no obliga bajo culpa, la ley, por su naturaleza, obligará bajo culpa sin más” (De lege, f. 435).

Finalmente, Soto se enfrenta a la objeción de que, si la ley impone una pena, por este solo hecho deja de obligar bajo culpa. En los tiempos de Soto existía la idea de que pena y culpa suponían obligaciones disyuntivas, esto es, que, si se mandaba la pena, no se mandaba la culpa, y viceversa. El dominico contesta diciendo que la amenaza con el castigo que se añade a la ley no significa que esta no obligue. Al contrario, es signo de que la ley obliga con más fuerza y de que ordena una acción cuyo cumplimiento es imprescindible para el logro del orden social. ${ }^{6}$ Por ende, la imposición de una pena no le resta eficacia a la vis directiva de la ley:

por tanto permanece asimismo aquella obligación. Se prueba la menor: la amenaza con el castigo de suyo tiene por objeto estimular con más diligencia el cumplimiento de la ley. Pues por esta razón se dijo [...] que el castigar tenía como fin que, así como en lo especulativo las conclusiones se manifiestan por los principios, así en lo práctico la observancia de los preceptos se hace saber por la amenaza del castigo. Por tanto el castigo no solo no es indicio de haber desaparecido el delito, sino por el contrario testimonio manifiesto de la gravedad que se contrae con la transgresión, u omisión de la ley (De iustitia et iure, I, 6, 5).

5 De lo contrario, pasará lo que, a juicio de Soto, pasa a un español respecto de las leyes francesas: no lo obligan a nada (De lege, f. 434).

6 Así, "cuanto más grave es la pena que acompaña la ley, es más claro que la culpa que se origina por el incumplimiento de la ley es muy grave” (De lege, f. 435). 
Cuando Suárez trata la cuestión de las leyes meramente penales, asume un principio básico de la doctrina de Soto: las leyes humanas, por lo menos, obligan a la pena. Dice, así, que la ley, si es justa, debe obligar a culpa o debe obligar bajo pena (De legibus, III, 22, 9). La autoridad puede escoger el tipo de ley que quiere dictar, pero no puede no imponer alguna obligación en el fuero interno (III, 22, 10).

Para que una ley sea tal, "basta que fuerce de alguna manera". Hay muchos institutos religiosos en los cuales "se dan verdaderas leyes o estatutos y en ellos se declara que no obligan bajo culpa sino bajo pena” (III, 22, 3). Esos estatutos son leyes verdaderas. ${ }^{7}$ El propio Tomás de Aquino — y, con él, Enrique de Gante y Alfonso de Castro — expone que cabe pensar en una norma que no obligue bajo culpa a los actos que manda o prohíbe (III, 22, 5).

Lo que observa Suárez con respecto a las normas de los religiosos se aplica, igualmente, al derecho civil. Muchas normas civiles "no mandan de una manera absoluta, sino que como quien dice — condicionalmente establecen que quien haga esto pague tal o cual pena" (III, 22, 6). A raíz de esto, escribe Suárez:

hay que decir que pueden darse leyes que coaccionen u obliguen bajo amenaza de pena aunque no obliguen en conciencia al acto por cuya trasgresión obligan a la pena. Esta tesis la supone como clara Azpilcueta [...] y la sostiene Vitoria; la demuestra también largamente Castro (V, 4, 2).

Suárez anota que en la ley humana se pueden reconocer dos obligaciones: una asociada a la culpa y otra asociada a la pena $(\mathrm{I}, 14,7){ }^{8} \mathrm{Si}$ solo se impone una acción u omisión, sin añadir una pena por la inobservancia de la ley, la ley será puramente moral. Si se impone una acción u omisión y se ordena sufrir un castigo por la infracción de la ley, la ley será mixta.Y si solo se manda sufrir una pena por el incumplimiento de la norma, la ley será meramente penal $(\mathrm{V}, 4,2)$. Esta manera de obligar no es contraria a la justicia ni a la esencia de la ley. La autoridad puede, "a su prudente arbitrio, querer sola esa manera y no otra; luego en el caso de que lo haga así, creará una ley puramente penal que obligue al acto mandado no en conciencia sino solamente bajo pena" (V, 4, 3).

Suárez expresa que no hay duda sobre esta conclusión: "porque cayendo ambas obligaciones

7 Acerca de las normas de los institutos religiosos, escribe Suárez: “En la apreciación general son verdaderas constituciones y estatutos, y así las llaman los pontífices cuando dan poder para crearlas. Además son actos de jurisdicción y de un poder superior que impone alguna necesidad de obrar así; luego sobrepasan el concepto de consejo y no son solo convenios, pues aunque suponen el consejo en el sentido de que al principio fue necesaria la profesión de tal estado, después la obligación nace de la jurisdicción. Por eso algunos creen que para el concepto de ley basta que imponga obligación, sea bajo culpa sea bajo pena” (De legibus, V, 4, 4).

8 "Dos elementos hay que distinguir en la ley penal: el uno se refiere al acto que pretende que se realice u omita, el otro a la pena que [se] impone contra los trasgresores de tal ley" (De legibus, V, 3, 1). 
bajo el poder del legislador, este puede hacer uso de su poder como quiera dentro de lo que permite la justicia de la ley" $(\mathrm{V}, 4,3)$. Por eso, el legislador puede escoger entre la obligación a pena y la obligación a culpa. Ahora bien, cuando se dice que la ley puede no obligar más que a la pena,

esto se entiende con relación al acto que se manda o prohíbe a las inmediatas; sin embargo por ese hecho no es tal acto materia completa de esa ley: su materia completa es, la disyuntiva de hacer tal obra o de sufrir o cumplir tal pena, o - lo que viene a ser lo mismo - se trata de una ley condicional de pagar tal pena si no se hace tal cosa, y entonces no queda excluida de toda la disyuntiva la obligación en conciencia (III, 27, 3).

Aunque, de hecho, existen, las normas de esta clase no son la regla general. Lo común es que las leyes humanas obliguen a culpa. ${ }^{9}$ Luego, cuando expone que la fuerza para obligar en el fuero interno es esencial a la ley, Suárez parece tener en mente la obligación bajo culpa o pecado.

La presencia de una pena no excluye la obligación a culpa. Al igual que Soto, el jesuita entiende que la pena, en rigor, aumenta la obligación moral de la ley humana (pues reafirma su importancia como norma de coordinación social). Obligar a pena no se opone a obligación en conciencia (III, 27, 12). Es más, la obligación a pena es una forma de obligación en el fuero interno. Así, al añadir una pena, el legislador no revoca la fuerza directiva de la ley. Tampoco expresa una posible intención de no obligar o mandar. Los legisladores, señala Suárez, "no suelen añadir la amenaza de una pena para destruir su precepto sino para fortalecer y de alguna manera aumentar la obligación al menos en intensidad" (V, 3, 8).

\section{LA LEY INJUSTA}

La exposición de las ideas de Soto y de Suárez sobre la fuerza obligatoria de la ley humana no estaría completa si no se hiciese referencia al problema de las leyes injustas. Se suele pensar que la filosofía clásica niega que las leyes injustas obliguen a su cumplimiento. Se dice que la expresión lex iniusta non est lex significa que siempre se deben resistir las normas contrarias al orden de la ley natural. Si bien es cierto que, para los autores clásicos (como santo Tomás, Cayetano, Francisco de Vitoria, etc.), la obligación de la ley humana deriva de su conformidad con los principios naturales, hay casos en que incumplir una ley injusta produce un perjuicio mayor que obedecerla.

9 Anota Suárez: "cuando no hay ninguna razón para presumir que una ley sea injusta y consta que ha sido dada por un superior legítimo, ciertamente obliga” (De legibus, V, 18, 18). 
Los pensadores de la Escolástica plantean que una cosa es que la ley injusta no obligue per se y otra que obligue per accidens o de manera colateral. Las leyes contrarias al bien común no son leyes en un sentido primario o principal; pero siguen siendo leyes en un sentido derivado o lato. Que no sean leyes en sentido primario no quiere decir que se deban resistir a todo evento. Los escolásticos — medievales y renacentistas — distinguen entre una ley injusta que manda hacer positivamente el mal, que siempre se debe rechazar, y una ley injusta que manda padecer un mal, que, en ocasiones, se debe cumplir para evitar el escándalo o para evitar un mal mayor. Las leyes de este segundo tipo pueden obligar en forma colateral o derivada. Es este el escenario en que Soto y Suárez desarrollan su explicación sobre la ley injusta.

Soto parte de la idea de que para entender la cuestión de la fuerza obligatoria de la ley humana "es necesario distinguir entre leyes justas e injustas". Señala que la ley injusta, en principio, no obliga, que las leyes que contradicen el orden de la ley natural siempre se deben desobedecer, y que esas leyes, como carecen de rectitud, no pueden ser reglas y medidas de los actos humanos (De iustitia et iure, I, 6, 4). Lo anterior no significa que, para Soto, nunca haya que cumplir una ley injusta. Según se dijo, la tradición escolástica plantea que algunas veces es necesario — y hasta forzoso — cumplir una ley como esa: si se trata de leyes que mandan padecer un mal, y si el perjuicio de no cumplir esas leyes es mayor al perjuicio que se produce por cumplirlas, entonces se deben obedecer. Soto lo explica de la siguiente manera:

en aquellas leyes que no encierran en sí una tiranía manifiesta, no es posible resistir a los que tienen el poder, sin producir escándalo.Y por ello han de ser pacientemente respetadas, hasta que de una manera más suave se les abran los ojos y juzguen más cuerdamente. Pues aquí se cumple aquel consejo evangélico: si alguno te obligare a caminar con él mil pasos, acompáñale otros dos. Y a quien te arrebatare la túnica, dale también la capa. Pero si por el contrario algún tirano quisiera inducirnos con sus leyes a la idolatría, o apartarnos de nuestros sacramentos, o arrastrarnos a otras costumbres, o ritos contrarios a nuestra fe, entonces no hemos de reparar en escándalos, porque mayor escándalo sería si, con desprecio de la vida, no nos opusiéramos a ellas inmediatamente $(\mathrm{I}, 6,4)$.

La ley que contradice el bien divino se debe resistir porque "hay que obedecer a Dios antes que a los hombres" $(I, 6,4)$. Una ley como esta nunca se ha de cumplir, pues atenta contra una de las reglas más elementales de la ética cristiana: amar a Dios sobre todas las cosas. Luego, anota Soto, es absolutamente injusta (De lege, f. 433v). Respecto de las leyes que tratan sobre el bien humano, estas se dirán justas de acuerdo con su fin — en la medida en que se ordenen al bien común_- con su autor — siempre que la autoridad no exceda el ámbito de sus potestades_- o con su forma — cuando sean iguales para todos_- En este sentido, escribe Soto: 
[l]a justicia de una ley depende de todas sus causas, que son final, eficiente, material y formal. Final, es decir, que la ley se ordene al bien común; porque, según hemos dicho ya, la misma diferencia existe entre las leyes que entre un tirano y un rey; y así se considera justa la que se ordena al bien común, y tiránica la que solo intenta el bien particular. Además ha de ser justa por parte de la causa agente, en el sentido de que quien la promulgue no traspase los términos de su jurisdicción [...] Por último ha de ser justa por parte de la causa formal. Porque siendo la ley una regla, su rectitud y justicia han de brillar de manera que observe con los ciudadanos, tanto en las recompensas como en las cargas, la misma proporción que ellos tengan con el cuerpo de la nación. Porque son como partes de un todo. Y por esta causa, así como la naturaleza ha repartido sus dones entre las partes, así también a cada ciudadano han de repartirse las cargas en proporción a sus fuerzas, y han de concedérseles los honores en proporción a sus dignidades. Por tanto la ley que estuviere concebida en estas condiciones, será obligatoria (De iustitia et iure, I, 6, 4).

Suárez, por su parte, indica que la ley injusta es violencia (De legibus, I, 9, 14), que es ley solo por analogía (I, 1, 6) y que no obliga en el fuero de la conciencia (III, 22, 1). Sostiene que la injusticia de las leyes humanas proviene, en general, de un defecto en la materia, porque se manda algo que la ley natural tiene por injusto o inconveniente. Por lo mismo, estas leyes no pueden ser aceptadas por la sociedad: no son medidas del bien del hombre $(\mathrm{I}, 1,6)$ :

la ley injusta no es medida de la rectitud de las acciones humanas, ya que — más bienla acción que a ella se ajusta es injusta; luego no es ley sino que recibe el nombre de ley solo por cierta analogía en cuanto que prescribe una determinada manera de obrar en orden a un fin $(I, 1,6)$.

No todas las normas injustas lo son de la misma forma. Hay leyes absolutamente injustas, como la que manda hacer un mal, y leyes parcialmente injustas, como la que grava al ciudadano con cargas desproporcionadas. Las primeras nunca se deben cumplir. Las segundas, en cambio, obligan algunas veces: cuando su infracción produce un mal mayor que su cumplimiento.

En algún sentido, dictar leyes injustas es inevitable: "el legislador humano no tiene una voluntad perfecta como la tiene Dios, y por eso [...] a veces — como es claro—, puede mandar cosas injustas" (I, 9, 4). Esto no quiere decir que los hombres tengan poder para dar normas injustas. Solo significa que los hombres son como causas segundas dotadas de un poder legislativo falible, imperfecto y participado. 


\section{CONCLUSIÓN}

Soto y Suárez, aunque integran la misma tradición filosófica, no llegan a las mismas conclusiones cuando se enfrentan al problema de si la ley humana obliga en el fuero interno. Si bien ambos autores construyen sus argumentos a partir del principio de que la ley humana siempre obliga, no están de acuerdo en lo que se refiere a la existencia de normas meramente penales, esto es, de leyes que no obligan a culpa moral sino solo a sufrir una pena por su incumplimiento.

Soto, que, inicialmente, niega la existencia de leyes puramente penales, al poco andar expone que las leyes que no obligan a culpa, como las constituciones de los dominicos, pueden darse también en la sociedad civil. Intentando ser coherente con su propuesta general, que parte del supuesto de que las leyes humanas, si son justas, obligan bajo culpa moral, sugiere que las normas que parecen puramente penales no imponen, en realidad, castigos o penas sino tributos o precios para quienes han decidido infringirlas. Luego, dice, no hay acá leyes meramente penales. Suárez, notando la falta de consistencia de los argumentos sotianos, observa que sí hay leyes penales puras, "como los estatutos de muchas órdenes religiosas”, y que la existencia de leyes que no obligan a culpa no es contraria al orden de la razón natural. Solo hay que tener presente que "obligar en conciencia" no significa exclusivamente "obligar a culpa"; también quiere decir "obligar bajo pena".

Las diferencias entre estos autores desaparecen cuando tratan el problema de la obligatoriedad de la ley injusta. Tanto Soto como Suárez no piensan que siempre haya que resistir las leyes injustas. La expresión agustiniana de que "la ley injusta no es ley" no significa que las normas contrarias al bien humano no sean leyes en ningún sentido, sino solo que no son leyes en sentido primario o focal. Por eso, algunas veces, estas leyes sí se deben obedecer, cuando, aunque manden padecer un mal, su incumplimiento sea más grave o produzca más perjuicios que su cumplimiento.

\section{NOTA DE AGRADECIMIENTO}

El autor agradece el patrocinio de Fondecyt-Chile, proyecto 3140035, y el patrocinio de Becas Chile, Beca de pasantía doctoral 2014.

\section{REFERENCIAS}

AQUINO, Tomás de. Opera omnia, según la edición electrónica de Enrique Alarcón: Corpus Thomisticum, recognovit ac instruxit Enrique Alarcón automato electronico, Pampilonae ad Universitatis Studiorum 
Navarrensis aedes A. D. MMV, en <http://www.corpusthomisticum.org/iopera.html>.

SOTO, Domingo de. De iustitia et iure libri decem. De la justicia y el derecho en diez libros, Madrid, Instituto de Estudios Políticos, 1967-1968.

De lege, ms. ottob. lat. 782, Biblioteca Vaticana.

SUÁREZ, Francisco. Defensa de la fe católica y apostólica contra los errores del anglicanismo, Madrid, Instituto de Estudios Políticos, 1970-1971.

Tratado de las leyes y de Dios legislador en diez libros, Madrid, Instituto de Estudios Políticos, 1967-1968.

VIO, Tomás de (Cayetano). Commentaria in Summam theologice S. Thomæe Aquinatis, Romæ, Leonina, 1888-1906.

Sebastián Contreras

Profesor de Filosofía del Derecho, Facultad de Derecho, UNIVERSIDAD DE LOS ANDES. scalamiuandes.cl 